\title{
Effect of ulinastatin on the expression and distribution of high mobility group box 1 in human colon carcinoma cells in vitro
}

\author{
YUNHUA WANG ${ }^{1}$, TAO TAO $^{2}$, YINV DONG $^{2}$, JING ZHANG $^{2}$ and ZAISHENG QIN ${ }^{2}$ \\ ${ }^{1}$ Department of Anesthesiology, The First People's Hospital of Foshan and Foshan Hospital of Sun Yat-Sen University, \\ Foshan, Guangdong 528000; ${ }^{2}$ Department of Anesthesiology, Nanfang Hospital of Southern Medical University, \\ Guangzhou, Guangdong 510515, P.R. China
}

Received December 30, 2013; Accepted September 18, 2014

DOI: $10.3892 / \mathrm{mmr} .2014 .2921$

\begin{abstract}
The aim of the present study was to investigate the in vitro effects of ulinastatin (UTI) on the proliferation, invasion, apoptosis, expression and distribution of high mobility group box 1 (HMGB1) and the expression of nuclear factor $\kappa \mathrm{B}(\mathrm{NF}-\kappa \mathrm{B})$ in human colon carcinoma LoVo cells. The cells were divided into control (untreated), UTI1 (400 U/ml UTI), UTI2 (800 U/ml UTI) and UTI3 (1,600 U/ml UTI) groups. The cell proliferation, invasion, apoptosis and the gene and protein expression of HMGB1 and NF- $\mathrm{HB}$ were detected using a tetrazolium assay, Transwell cell invasion assays, a caspase-3 activity assay, western blot analysis and reverse transcription quantitative polymerase chain reaction, respectively. The distribution of HMGB1 was detected using immunofluorescence. LoVo cell proilferation decreased the most in the UTI3 group followed, in order, by the UTI2, UTI1 and control groups. UTI inhibited invasion in LoVo cells and the inhibitory effect was enhanced as the UTI concentration increased. The activity of caspase- 3 increased the least in the control group followed, in order, by the UTI1, UTI2 and UTI3 groups. UTI inhibited the expression of HMGB1 and NF- $\mathrm{B}$, and decreased the cytoplasmic distribution of HMGB1. Thus, UTI inhibited LoVo cell proliferation and induced LoVo cell apoptosis, the mechanism of which may be associated with a decreased in the expression of HMGB1 and $\mathrm{NF}-\kappa \mathrm{B}$, and the cytoplasmic distribution of HMGB1.
\end{abstract}

\section{Introduction}

High mobility group box 1 (HMGB1, formerly HMG1) was originally described as a non-histone chromatin-associated nuclear protein (1-4). The HMGB1 sequence is highly

Correspondence to: Mr. Zaisheng Qin, Department of Anesthesiology, Nanfang Hospital of Southern Medical University, 1838 Guangzhou Avenue North, Baiyun, Guangzhou, Guangdong 510515, P.R. China

E-mail: qinzaisheng1100@163.com

Key words: ulinastatin, LoVo cells, high mobility group box 1, nuclear factor $\kappa \mathrm{B}$ conserved among species, with murine HMGB1 differing in only two amino acids to that in humans. HMGB1 consists of two tandem L-shaped domains, HMGB boxes A and B, which are $\sim 75$ amino acids in length, and a highly acidic carboxyl terminus, which is 30 amino acids in length. HMG proteins are small, DNA-binding proteins that are important in transcriptional regulation (5). In HMGB1-deficient mice, mortality occurs within a few hours of birth, demonstrating the important role of this protein in cellular function. In cellular systems, HMGB1 is considered to have two separate functions It is an intracellular regulator of transcription and has an extracellular role, in which it promotes metastasis (6-9). Overexpression of the HMGB1 protein is linked to the following cancer-associated characteristics: Unlimited proliferation, angiogenesis, resistance to apoptosis, the production of growth factors by cells, lack of susceptibility to growth inhibitors, inflammation and metastasis (10). It has also been demonstrated that the protein is involved in cell invasion, tumor growth and metastasis (11). Treatment with anti-HMGB1 antibodies in mice leads to the suppression of metastasis in Lewis lung tumor cells implanted beneath the skin (12). The HMGB1 protein has been detected in various types of tumor. Compared with normal tissues, the HMGB1 protein is commonly overexpressed in gastric and colorectal adenocarcinoma (13). The HMGB1 protein is also upregulated in melanomas (14) and high levels of the protein are observed in leukemia cells (15). There is marked intertumoral variation in the expression of HMGB1 in different types of breast cancer (16). Although HMGB1 is overexpressed in the majority of types of tumor, certain tumors contain no HMGB1 protein, including adrenal gland carcinoma, in which no HMGB1 expression is observed (17). It is hypothesized that the HMGB1 protein affects cell invasion, tumor growth and metastasis by high-affinity binding to the receptor for advanced glycation end products (RAGE) $(12,18)$. HMGB1, which has been identified as a RAGE ligand, is secreted by certain types of cell and is important in inflammation, cell migration, differentiation and tumorigenesis $(19,20)$. The binding of HMGB1 to RAGE activates key cell signaling pathways, including those of mitogen-activated protein kinases (MAPKs) and nuclear factor (NF) (11). HMGB1 may act as a mediator of angiogenesis, increasing the expression of angiogenic growth factors, including vascular endothelial growth factor (21). HMGB1 has been observed to lead to endothelial cell migration and 
sprouting in vitro (22), mediate the upregulation of vascular endothelial growth factor $\mathrm{C}$ and enhance lymphangiogenesis (23). Overexpression of HMGB1 suppresses the activity of caspase- 9 and capsase-3, suggesting that it interferes with the apoptotic mechanism at the level of apoptosomal caspase-9 activation. The apoptosis-repressing HMGB1 and cellular inhibitor of apoptosis 2 (c-IAP2) proteins are upregulated in the pathogenesis of colon carcinoma (24). Clinical studies have demonstrated that HMGB1-knockdown inhibits the metastatic potential of cancer cells (25). Therefore, the HMGB1 ligand or its receptor are important targets as a possible application in cancer therapeutics (26). Ulinastatin (UTI) is a Kunitz-type protease inhibitor (27) and an effective calcium influx inhibitor of the cell transporter system (28). Kobayashi et al demonstrated that there are specific UTI binding sites on the surfaces of certain tumor cells and exogenously applied UTI binds to these sites. This potentially leads to the buildup of a substantial quantity of UTI on the tumor cell surface (29). There is clear evidence that UTI is important in preventing tumor cell invasion and metastasis $(30,31)$. UTI also inhibits tumor necrosis factor $\alpha$ (TNF- $\alpha$ )-mediated translocation, protein kinase C (PKC) activation (32) and the phorbol myristate acetate (PMA)-dependent activation of the PKC and MAPK cascade (31). Kobayashi et al observed that UTI inhibited tumor invasion and metastasis, possibly through the suppression of cell-associated plasmin activity and the mRNA and protein expression of urokinase plasminogen (uPA). In endotoxemic rats, UTI suppresses excessive superoxide $\left(\mathrm{O}_{2}^{-}\right)$generation, systemic inflammation, lipid peroxidation and HMGB1 (33). However, the potential role of UTI in the regulation of HMGB1 in cancer remains to be elucidated. The present study aimed to determine the effect of the exogenous UTI in the expression of HMGB1 and investigate the effect of UTI inhibition on the activity and release of HMGB1.

\section{Materials and methods}

Cell culture. The human colon cancer cell line LoVo, was provided by Dr Ma (Key Laboratory of Antibody Engineering, Department of Education, Guangdong, China). The cell line was negative for mycoplasma contamination. Cells were maintained in Dulbecco's modified Eagle's medium (DMEM) supplemented with penicillin $(100 \mathrm{U} / \mathrm{ml})$, streptomycin $(100 \mathrm{U} / \mathrm{ml})$ and $10 \%$ heat-inactivated fetal bovine serum (Gibco Life Technologies, Grand Island, $\mathrm{NY}, \mathrm{USA}$ ) at $37^{\circ} \mathrm{C}$ in $5 \% \mathrm{CO}_{2}$.

Drug assay. The cells were divided into the four following groups for the drug assay: Control (no UTI), UTI1 (400 U/ml UTI), UTI2 (800 U/ml UTI) and UTI3 (1,600 U/ml UTI). Prior to stimulation, the cells were washed three times with $\mathrm{NaCl}$ /propidium iodide (Sigma Co., St. Louis, MO, USA) and incubated overnight in complete medium containing $1 \%$ fetal bovine serum. The test drug was added and the incubation was continued for different durations $(24,48$ or $72 \mathrm{~h}$ ). Subsequently, the medium was aspirated and the cells were harvested and washed thoroughly with phosphate-buffered saline (PBS). The cell viability immediately prior to harvesting remained $>90 \%$.

Cell growth. The cultured cells were harvested from $80 \%$ confluent monolayers by brief trypsinization with
$0.1 \%$ trypsin and $0.1 \%$ ethylenediaminetetraacetic acid (Gibco Life Technologies, Carlsbad, CA, USA). The cells $(2,000$ cells/well) were seeded onto 96-well tissue culture plates (Corning Inc., New York, NY USA) and were cultured for $12 \mathrm{~h}$ in regular medium. The cells were washed twice with PBS and treated with UTI. The cell growth was monitored following 24, 48 and $72 \mathrm{~h}$ by MTT assay (36). All experiments were repeated three times under the same conditions.

Invasion assay. Using a Boyden chamber system, the capability of tumor cells to invade was assessed using previously described methods (34). A polycarbonate membrane with $8 \mu \mathrm{m}$ pores was coated with a reconstituted basement membrane gel (Matrigel; BD Biosciences, Franklin Lakes, USA). DMEM containing $10 \%$ fetal bovine serum was placed in the lower compartment of the chamber as a chemoattractant. The UTI-treated LoVo cells $\left(1 \times 10^{5}\right)$ were resuspended in complete medium $(200 \mu \mathrm{l})$ and seeded in the upper chamber. Following incubation for $24 \mathrm{~h}$ at $37^{\circ} \mathrm{C}$, the cells that had migrated to the lower chamber were fixed and stained using $0.1 \%$ crystal violet (Sigma) and counted using fluorescence microscopy (Olympus IX71; Olympus, Tokyo, Japan; magnification, x100).

Western blot analysis. The HMGB1 $\mathrm{NF}-\kappa \mathrm{B}$ protein was detected by immunoblotting. The conditioned media were individually harvested and the remaining monolayers were scraped and lysed in lysis buffer containing $50 \mathrm{mM}$ 4-(2-Hydroxyethyl) piperazine-1-ethanesulfonic acid, $0.5 \mathrm{mM} \mathrm{NaCl}, 0.05 \%$ Tween-20, $1 \%$ Triton X-100, $1 \mathrm{mM}$ phenylmethanesulfonyl fluoride, $10 \mu \mathrm{g} / \mathrm{ml} \mathrm{E}-64$ and $10 \mu \mathrm{g} / \mathrm{ml}$ leupeptin, to prepare the cell lysates. Equal quantities of cellular protein (50 $\mu \mathrm{g} /$ lane) underwent $12 \%$ SDS-PAGE and were transferred to polyvinylidene difluoride membranes (Roche, Mannheim, Germany). The membrane was probed for $12 \mathrm{~h}$ with anti-HMGB1 rabbit polyclonal antibody (1:1,000; Abcam, Cambridge, UK) or anti-NF- $x \mathrm{~B}$ rabbit polyclonal antibody $(1: 1,000$; Abcam), Horseradish peroxidase-conjugated anti-rabbit immunoglobulin G (1:5,000; Abcam) was used as secondary antibody and was incubated for $2 \mathrm{~h}$. Immunoreactivity was detected using an Enhanced Chemiluminescence kit (Thermo Fisher Scientific, Waltham, MA, USA) and visualized using Image Gauge software (Fujifilm, Tokyo, Japan).

Immunofluorescence image analysis. The cells were cultured in 96-well plates and fixed using $10 \%$ paraformaldehyde in PBS for $10 \mathrm{~min}$ at room temperature. The cells were then washed with PBS and incubated for $5 \mathrm{~min}$ at $4^{\circ} \mathrm{C}$ with permeabilization buffer, containing $0.1 \%$ Triton $\mathrm{X}-100$ in PBS. The samples were blocked using $2 \%$ bovine serum albumin (BSA) in PBS for $30 \mathrm{~min}$ and incubated with rabbit anti-HMGB1 (1:100) for $24 \mathrm{~h}$ at $4^{\circ} \mathrm{C}$. Following washing three times with $0.2 \% \mathrm{BSA}$ in PBS, an Alexa Fluor 488 secondary antibody (1:50; Invitrogen Life Technologies, Carslbad, CA, USA) was added for $1 \mathrm{~h}$ at room temperature. Mounting medium containing Hoechst (1:50; Vector Laboratories, Inc., CA, USA) was used for $30 \mathrm{~min}$ at room temperature. Fluorescent-labeled cells were observed using an inverted microscope (Olympus, Tokyo, Japan) and images were captured using XV Image processing software (Mathworks, Natick, MA, USA). 
Caspase activity assay. Caspase activity was quantified using a Caspase-3 Fluorometric Protease assay kit (BioVision, Inc, Milpitas, CA, USA) according to the manufacturer's instructions. All components mentioned in this paragrph are part of the Caspase Assay kit. The assay was based on the cleavage of the fluorogenic peptide DEVD-AFC, a caspase-3 substrate, which was added to the cell lysates prepared from the apoptotic cells and the non-apoptotic controls. The cells $\left(1 \times 10^{6}\right)$ were counted, pelleted and resuspended in $50 \mu \mathrm{l}$ chilled cell lysis buffer prior to incubation on ice for $10 \mathrm{~min}$. A reaction buffer $(2 \mathrm{X} ; 50 \mu \mathrm{l})$ containing $10 \mathrm{mM}$ dithiothreitol was added to each sample, followed by $5 \mu 11 \mathrm{mM}$ DEVE-AFC substrate to a final concentration of $50 \mu \mathrm{M}$ and incubated at $37^{\circ} \mathrm{C}$ for $1.5 \mathrm{~h}$. The samples were transferred onto a 96-well plate for detection of caspase activity and were read using an automatic fluorometer microplate reader (SpectraMax M5; Molecular Devices, Sunnyvale, CA, USA) equipped with a $400 \mathrm{~nm}$ excitation filter and $505 \mathrm{~nm}$ emission filter.

Reverse transcription and quantitative polymerase chain reaction $(q P C R)$. The total RNA extracts $(2 \mu \mathrm{g})$ from the LoVo cells or control cells were reverse-transcribed using Expand Reverse Transcriptase (Roche Diagnostics, Basel, Switzerland) according to the manufacturer's instructions. The cDNA was then used for qPCR. Primers were designed using the Primer Express program (PerkinElmer, Inc., Waltham, MA, USA). Quantification of the target cDNA was performed using an ABI PRISM 7500HT Sequence Detection system (Applied BiosystemsLife Technologies, Foster City, CA, USA), using SDS 2.1 software (Applied Biosystems Inc., Carlsbad, CA, USA). All reactions were performed three times in triplicate. The transcripts were detected using SYBR Green I (Applied Biosystems) according to the manufacturer's instructions and were normalized to the internal control $\beta$-actin and optimal reaction conditions for target gene amplification were according to the manufacturer's instructions. Primers were designed using the primer design software, Primer 5.0 (Shanghai Biotechnology Co., Ltd., Shanghai, China). The primer sequences used were as follows: Forward, 5'-TGAGCTCCATAGAGACAGCG-3', and reverse, 5'-TGACATTTTGCCTCTCGGCT-3'.

Statistical analysis. Data are expressed as the means \pm standard deviation. All statistical analyses were performed using SPSS 18.0 software (SPSS, Inc., Chicago, IL, USA). The Mann-Whitney U test was used to compare the different groups. $\mathrm{P}<0.05$ was considered to indicate a statistically significant difference.

\section{Results}

LoVo cell proliferation. The proliferation of UTI-treated LoVo cells were significantly inhibited compared with the control group $(\mathrm{P}<0.05)$. The inhibitory effect was enhanced following extended treatment, which indicated a time-dependent effect (Fig. 1). Similarly, the inhibitory effect increased significantly as the UTI concentration increased.

In vitro invasion. Following treatment (48 h), the number of UTI1 cells that had invaded the membrane were

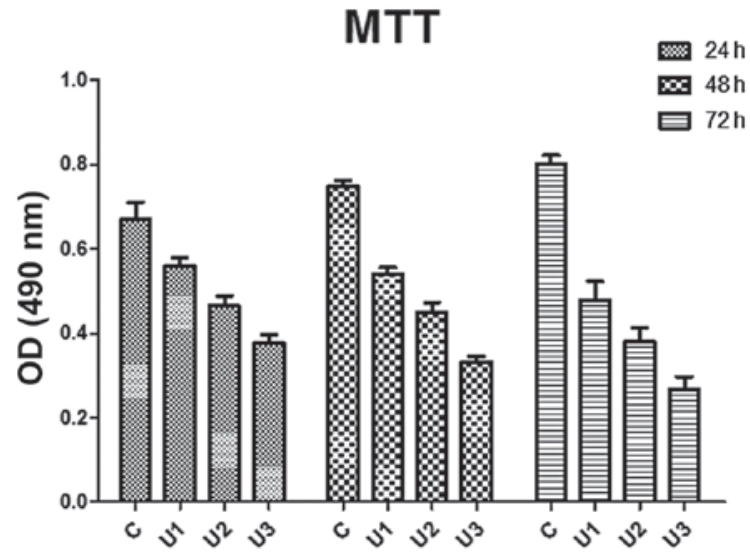

Figure 1. Effect of UTI on LoVo cell growth. Compared with the control, the growth rates of the UTI1-3 LoVo cells were reduced by $16.29,30.62$ and $43.73 \% ; 27.69,39.95$ and $55.62 \%$; and $40.24,52.52 \%$ and $65.62 \%$, respectively, after 24,48 , and $72 \mathrm{~h}$. The cells were reseeded into 96 -well culture plates and growth was assessed by MTT assay. Each value is expressed as the mean of three experiments and the error bars denote the standard deviation. C, control; U1, cells treated with $400 \mathrm{U} / \mathrm{ml} \mathrm{UTI}$; $\mathrm{U} 2$, cells treated with $800 \mathrm{U} / \mathrm{ml} \mathrm{UTI}$; U3, cells treated with 1,600 U/ml UTI; UTI, ulinastatin; OD, optical density.

significantly lower (95 \pm 6 cells/well), as compared with the untreated cells $(153 \pm 11$ cells/well, $\mathrm{P}=0.0001$, unpaired Mann-Whitney U test; Fig. 2). The number of invading UTI2 cells was significantly lower $(38 \pm 5$ cells/well), as compared with the UTI1 cells ( $\mathrm{P}=0.0001$, unpaired Mann-Whitney $\mathrm{U}$ test). The number of invading UTI3 cells was significantly lower ( $15 \pm 3$ cells/well), as compared with the UTI2 cells $(\mathrm{P}=0.003$, unpaired Mann-Whitney $\mathrm{U}$ test $)$.

Caspase-3 activity. Using a fluorescent substrate peptide, the caspase-3 activity in cell lysates, prepared from UTI-treated LoVo cells, was measured. UTI effectively enhanced caspase-3 activity (Fig. 3) and a significant difference $(\mathrm{P}<0.05)$ was observed between the UTI groups.

Immunofluorescence imaging. Cytoplasmic HMGB1 was observed in the control cells (Fig. 4). In the UTI-treated cells, HMGB1 was present mainly in the nucleus, indicating that the distribution of HMGB1 had been altered. All data are representative of two or three experiments. Fig. 4 depicts the UTI1 cells.

Effects of UTI on the expression of HMGBI. The LoVo cells were exposed to UTI for $48 \mathrm{~h}$ and the mRNA and protein expression of HMGB1 were examined by qPCR (Fig. 5) and immunoblotting (Fig. 6A). The mRNA levels of HMGB1 were reduced following UTI treatment in comparison with the control group. The mRNA level of HMGB1 in the control cells remained unaltered. The protein levels of HMGB1 the in UTI1, UTI2 and UTI3 cells were reduced by 14.48, 31.69 and $43.56 \%$, respectively, compared with the control cells.

Effects of UTI on the protein expression of $N F-\kappa B$. The LoVo cells were exposed to UTI for $48 \mathrm{~h}$ and the protein expression of $N F-\kappa B$ was examined using immunoblotting (Fig. 6B). The results demonstrated that UTI significantly inhibited 

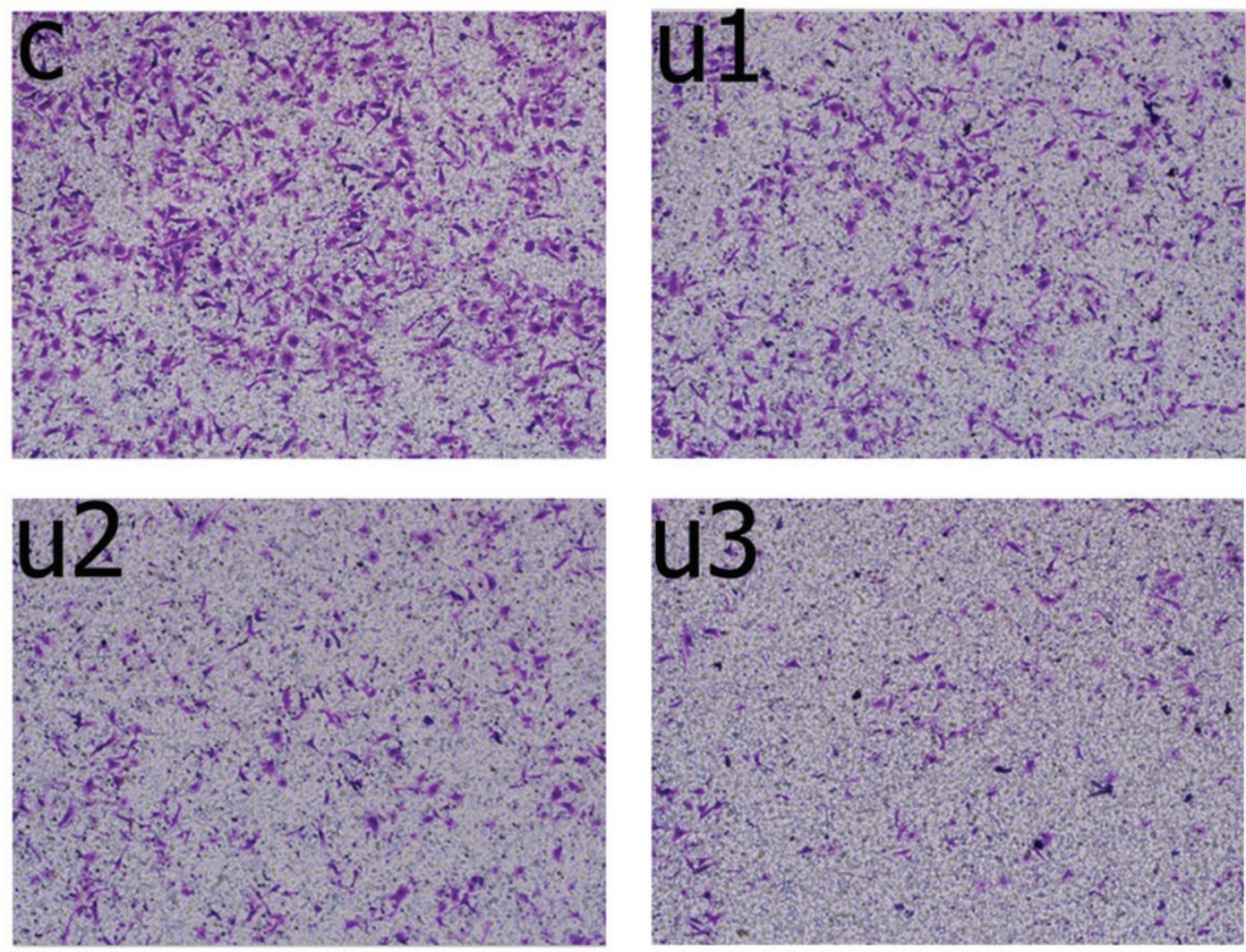

Figure 2. In vitro invasion assay. UTI-treated LoVo cells were incubated in a modified Boyden chamber. After $24 \mathrm{~h}$, the cells invading the type IV collagen matrix were counted (magnification, x100). C, Control; U1, cells treated with $400 \mathrm{U1} / \mathrm{ml}$ UTI; U2, cells treated with $800 \mathrm{U} / \mathrm{ml}$ UTI; U3, cells treated with 1,600 U/ml UTI; UTI, ulinastatin.

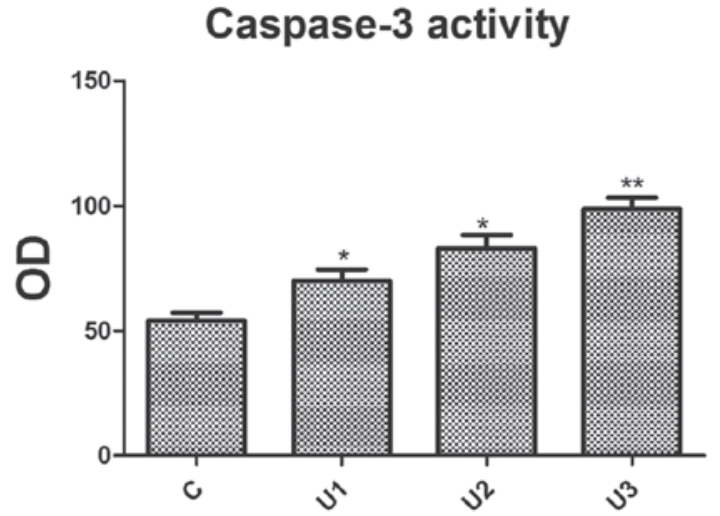

Figure 3. Caspase-3 activity following UTI exposure was increased in the LoVo cells compared with the controls. The results are representative of three separate experiments. C, control; U1, cells treated with $400 \mathrm{U} / \mathrm{ml}$ UTI; U2, cells treated with $800 \mathrm{U} / \mathrm{ml}$ UTI; U3, cells treated with 1,600 U/ml UTI. UTI, ulinastatin; OD, optical density. ${ }^{*} \mathrm{P}<0.05,{ }^{* *} \mathrm{P}<0.01$ as compared group $\mathrm{C}$.

the protein expression of $\mathrm{NF}-\kappa \mathrm{B}$ compared with the control group $(\mathrm{P}<0.05)$.

\section{Discussion}

HMGB1 is a nuclear protein that is involved in the process of carcinogenesis (35). HMGB1 is upregulated in certain types of tumor, including colon adenoma and carcinoma and HMHB1 overexpression is observed in prostate cancer and malignant melanoma cells $(14,36,37)$. HMGB1 is also overexpressed in colorectal cancer cells (HCT116, HT-29, SW480 and DLD-1), derived from primary lesions and LoVo and SW620 cells, derived from metastatic lymph nodes (38). Overexpression of HMGB1 promotes cell motility, invasiveness, proliferation and angiogenesis in cancer progression (39) and results in the release or secretion of higher quantities of the protein in the tumor microenvironment. This confers a selective advantage to cancer cells, promoting more effective angiogenesis and facilitating metastatic spread (35). Overexpression of HMGB1 inhibits apoptosis while increasing the activity of NF- $\mathrm{KB}$ and leads to the overexpression of the anti-apoptotic NF- $\mathrm{kB}$ target gene product c-IAP2 in vitro. Further analysis has revealed a correlation between increased levels of HMGB1 and increased quantities of c-IAP2 in colon tumors. The overexpression of HMGB1 also inhibits the activity of caspase-9 and caspase-3 (24). Released HMGB1 activates tumor-associated macrophages and cancer cells, resulting in the secretion of proinflammatory cytokines, including TNF- $\alpha$, interferon-c and interleukin (IL)-1b (40). This further stimulates the division of cancer cells and endothelial cells, the latter leading to neoangiogenesis $(41,42)$. It has been demonstrated that UTI inhibits the release TNF- $\alpha$, IL-1 and IL-6, prompting investigation of the therapeutic use of UTI in the inhibition of HMGB1 activity. UTI significantly prevents the pulmonary metastasis of mouse Lewis lung carcinoma 3LL cells significantly (43) and it has been suggested that UTI is important in inhibiting the invasion and metastasis of tumor cells (44), possibly by the direct inhibition of cell-associated plasmin 
HMCB1
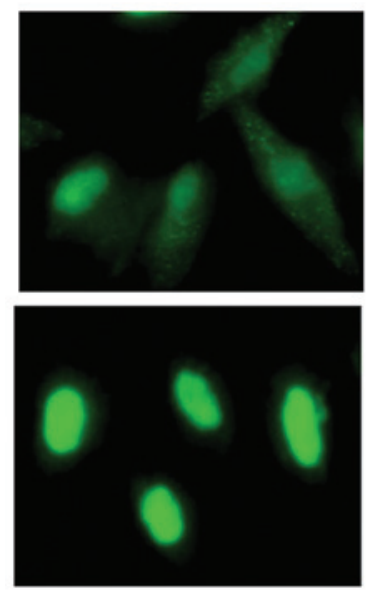

Hoechst
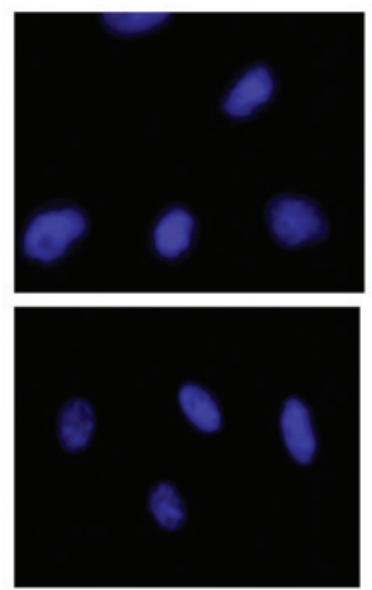

Merge
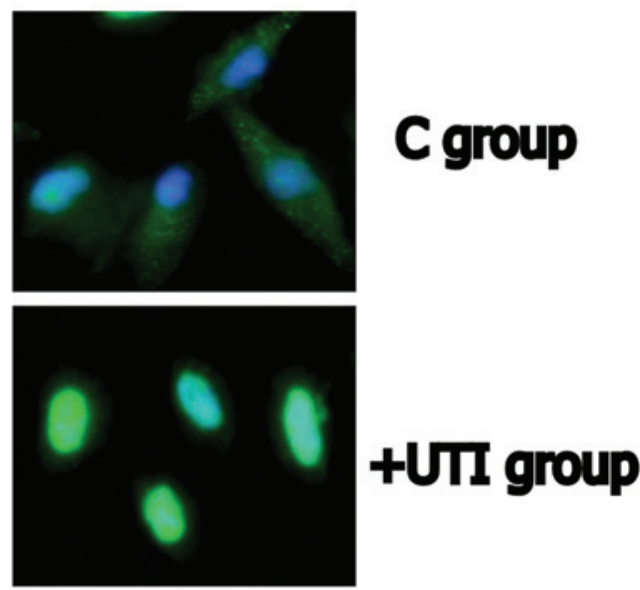

Figure 4. Localization of HMGB1 in the LoVo cells treated with $400 \mathrm{U} / \mathrm{ml}$ UTI. Nuclear and cytoplasmic localization was observed. Cytoplasmic HMGB1 expression was significantly decreased following UTI treatment. C, Control; UTI, ulinastatin; HMGB1, high mobility group box 1.

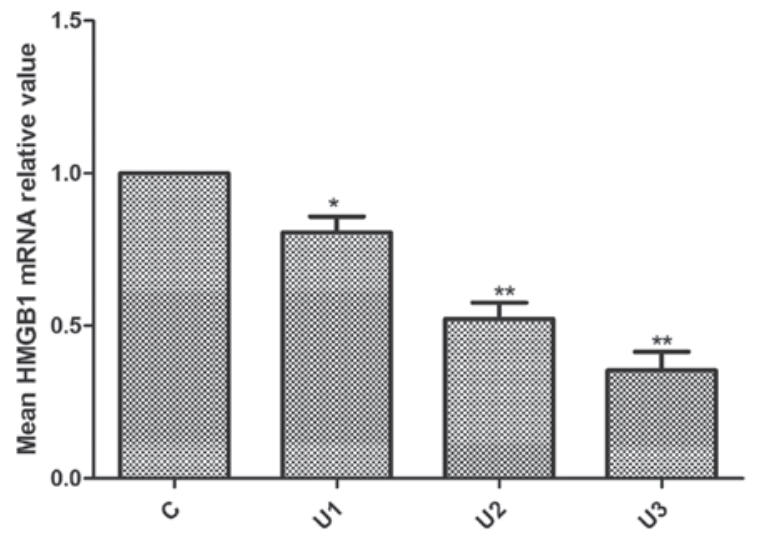

Figure 5. Effects of UTI on the mRNA levels of HMGB1. Results are expressed as the mean \pm standard deviation of four different readings with $\beta$-Actin as an internal control. UTI, ulinastatin; C, control; U1, cells treated with $400 \mathrm{U} / \mathrm{ml}$ UTI; U2, cells treated with $800 \mathrm{U} / \mathrm{ml}$ UTI; U3, cells treated with $1,600 \mathrm{U} / \mathrm{ml} \mathrm{UTI}$. HMGB1, high mobility group box 1 . ${ }^{*} \mathrm{P}<0.05,{ }^{* *} \mathrm{P}<0.01$ as compared group $\mathrm{C}$.

activity and by inhibiting the mRNA expression of uPA and its receptor UPAR (45). UTI also inhibits the upregulated expression of UPA and UPAR, possibly through MAPK-dependent signaling cascades, in ovarian carcinoma cells in vitro and in vivo (46) and UTI also downregulates the expression of CXC chemokine receptor 4 and matrix metalloproteinase-9 (47). In the present study, treatment with UTI significantly inhibited LoVo cell proliferation. RT-qPCR and western blot analysis demonstrated that UTI inhibited the expression of HMGB1 mRNA and protein, respectively, decreasing their expression in the UTI-treated LoVo cells, compared with the untreated control cells. A possible reason for this is that NF- $\kappa \mathrm{B}$ activation is required for the migration of cells to sites of tissue damage in response to the danger signal HMGB1 (48) and UTI may decrease NF- $\kappa$ B signal transduction (49). The present study also demonstrated that UTI inhibited NF- $\mathrm{NB}$. Brezniceanu et al (50) observed that the overexpression of HMGB1 inhibits Bak-induced cell death in the human colon
A

HMGB
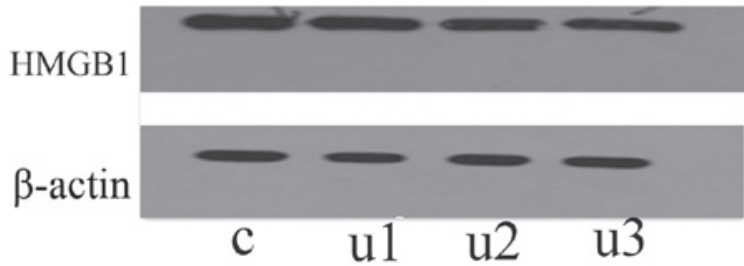

B

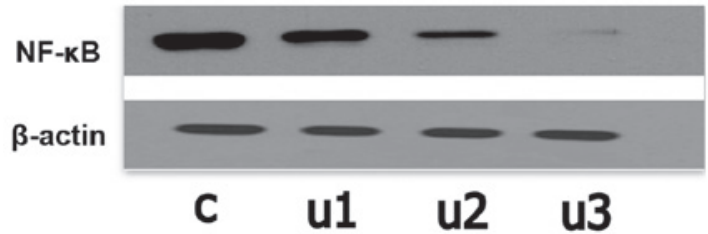

Figure 6. (A) Effect of UTI on the protein expression of HMGB1 in LoVo cells measured using ImageJ software. Images are representative electrophoresis results of the $30-\mathrm{kD}$ HMGB1 protein. A $43-\mathrm{kD} \beta$-actin fragment was used as the internal control. The relative quantity of HMGB1 protein is presented as the mean \pm standard deviation of the integrated optical density. (B) Effect of UTI on the protein expression of NF- $\kappa$ B in LoVo cells measured using ImageJ software. Images are representative electrophoresis results of the $65-\mathrm{kD} \mathrm{NF- \kappa B}$ protein. A $43-\mathrm{kD} \beta$-actin fragment was used as the internal control. The relative quantity of NF- $\mathrm{kB}$ protein is presented as the mean \pm standard deviation of the integrated optical density. UTI, ulinastatin; HMGB1, high mobility group box 1; C, Control; U1, cells treated with $400 \mathrm{U} / \mathrm{mL}$ UTI; U2, cells treated with $800 \mathrm{U} / \mathrm{mL}$ UTI; U3, cells treated with $1600 \mathrm{U} / \mathrm{mL}$ UTI.

carcinoma cell line, RKO. In the present study, UTI enhanced caspase-3 activity, possibly by inhibiting the expression of HMGB1. Another possibility is that UTI may have inhibited MAPK/extracellular signal-regulated signal kinase (ERK) kinase (MEK) 1/2 (45). Degryse et al (18) demonstrated that phosphorylated ERKs promote smooth muscle cell migration in response to HMGB1. ERK1/2 and MEK $1 / 2$ are rapidly phosphorized by HMGB1 in 3T3 fibroblasts and U0126, a MAPK/MEK 1/2-specific inhibitor, suppresses the migration induced by HMGB1 (18). HMGB1 stimulates ERK activity and it has been established that PMA induces ERK activity in a number of systems (51). It has been suggested that the effect of PMA on the expression of other genes is a result of 
activation of the classic pathway, the RAS/Raf-1/MEK/ERK signaling cascade (52). An alternative pathway involves the sequential activation of Rac1, MEK1, c-Jun N-terminal kinase (JNK) and the JNK subset of MAPK (50). UTI exerts its effects possibly through inhibition of the upstream components of ERK activation in the MAPK cascade, which are a set of signaling molecules that teleologically alter gene expression (45).

The present study also demonstrated that UTI altered the distribution of HMGB1. Cytoplasmic HMGB1 was entirely absent or present at low levels in normal tissues and normal fibroblast cell lines, whereas high levels of cytoplasmic HMGB1 were observed in the tumor cell. The decreased affinity of HMGB1 to bind to DNA may be associated with its transport into the cytoplasm. The cytoplasmic transport of HMGB1 results from its phosphorylation (53). Kang et al (54) observed that the secretion of HMGB1 is correlated with an increase in the invasiveness of cancer cells. Following transport into the cytoplasm, phosphorylated HMGB1 is secreted from the cell and the activation of genes associated with cell migration by phosphorylated HMGB1 affects tumor progression (54). In addition, the phosphorylation of serine 35, 39 and 42 of the nuclear localization signal 1 region in HMGB1 is essential for HMGB1 transport into the cytoplasm and these serine residues are consistent with the predicted PKC binding site (54). The PKC family is comprised of at least 12 serine-threonine kinases and these are divided into three major groups $(55,56)$. The most important cancer-associated targets of PKC are ERK1/2, glycogen synthase kinase-3 beta, NF- $\kappa B$ and P-glycoprotein $(57,58)$. The addition of phosphate groups to the HMGB1 protein decreases its DNA-binding activity and inhibits its accumulation in the nucleus. The nuclear or cytoplasmic localisation of HMGBl proteins may rely on their affinity for DNA (59). Therefore, the hypophosphorylated HMGB1 protein in cancer cells may increase its activitiy as a nuclear DNA-binding protein $(14,45)$. The present study demonstrated that UTI significantly decreased the movement of HMGB1 from the nucleus to the cytoplasm, which may have been caused by exogenous UTI-induced inhibition of the increased membrane-associated PKC and decreased cytosolic PKC activity (60). In conclusion, the present study demonstrated that UTI inhibited the expression of HMGB1 in LoVo cells.

\section{Acknowledgements}

This study was supported by grants from the National Natural Science Foundation of China (no. 81302758) and the President Fund of Nanfang Hospital (no. 2011B007).

\section{References}

1. Czura CJ, Wang H and Tracey KJ: Dual roles for HMGB1: DNA binding and cytokine. J Endotoxin Res 7: 315-321, 2001.

2. Agresti A and Bianchi ME: HMGB proteins and gene expression. Curr Opin Genet Dev 2: 170-178, 2003.

3. Andersson U, Erlandsson-Harris H, Yang H and Tracey KJ: HMGB1 as a DNA-binding cytokine. J Leukoc Biol 6: 1084-1091, 2002.

4. Muller S, Scaffidi P, Degryse B, et al: New EMBO members review: the double life of HMGB1 chromatin protein: architectural factor and extracellular signal. Embo J 20: 4337-4340, 2001.
5. Bustin M, Lehn DA and Landsman D: Structural features of the HMG chromosomal proteins and their genes. Biochim Biophys Acta 1049: 231-243, 1990.

6. Andersson U, Wang H, Palmblad K, et al: High mobility group 1 protein (HMG-1) stimulates proinflammatory cytokine synthesis in human monocytes. J Exp Med 192: 565-570, 2000.

7. Yang $\mathrm{H}$, Wang $\mathrm{H}$ and Tracey KJ: HMG-1 rediscovered as a cytokine. Shock 15: 247-253, 2001

8. Scaffidi P, Misteli T and Bianchi ME: Release of chromatin protein HMGB1 by necrotic cells triggers inflammation. Nature 418: 191-195, 2002.

9. Czura CJ and Tracey KJ: Targeting high mobility group box 1 as a late-acting mediator of inflammation. Crit Care Med 31: S46-S50, 2003.

10. Hanahan D and Weinberg RA: The hallmarks of cancer: the next generation. Cell 144: 646-674, 2011.

11. Sun KK, Ji C, Li X, et al: Overexpression of high mobility group protein $\mathrm{B} 1$ correlates with the proliferation and metastasis of lung adenocarcinoma cells. Mol Med Rep 7: 1678-1682, 2013.

12. Taguchi A, Blood DC, Del TG, et al: Blockade of RAGE-amphoterin signalling suppresses tumour growth and metastases. Nature 405: 354-360, 2000.

13. Xiang YY, Wang DY, Tanaka M, et al: Expression of high-mobility group-1 mRNA in human gastrointestinal adenocarcinoma and corresponding non-cancerous mucosa. Int J Cancer 74: 1-6, 1997.

14. Poser I, Golob M, Buettner R and Bosserhoff AK: Upregulation of HMG1 leads to melanoma inhibitory activity expression in malignant melanoma cells and contributes to their malignancy phenotype. Mol Cell Biol 23: 2991-2998, 2003.

15. Cabart P, Kalousek I, Jandová and Hrkai Z: Differential expression of nuclear HMG1, HMG2 proteins and H1(zero) histone in various blood cells. Cell Biochem Funct 13: 125-133, 1995.

16. Flohr AM, Rogalla P, Meiboom M, et al: Variation of HMGB1 expression in breast cancer. Anticancer Res 21: 3881-3885, 2001.

17. Muller S, Ronfani L and Bianchi ME: Regulated expression and subcellular localization of HMGB1, a chromatin protein with a cytokine function. J Intern Med 255: 332-343, 2004.

18. Degryse B, Bonaldi T, Scaffidi P, et al: The high mobility group (HMG) boxes of the nuclear protein HMG1 induce chemotaxis and cytoskeleton reorganization in rat smooth muscle cells. J Cell Biol 152: 1197-1206, 2001.

19. Guazzi S, Strangio A, Franzi AT and Bianchi ME: HMGB1, an architectural chromatin protein and extracellular signalling factor, has a spatially and temporally restricted expression pattern in mouse brain. Gene Expr Patterns 3: 29-33, 2003.

20. Hori O, Brett J, Slattery T, et al: The receptor for advanced glycation end products (RAGE) is a cellular binding site for amphoterin. Mediation of neurite outgrowth and co-expression of rage and amphoterin in the developing nervous system. J Biol Chem 270: 25752-25761, 1995.

21. Ono M, Torisu H, Fukushi J, et al: Biological implications of macrophage infiltration in human tumor angiogenesis. Cancer Chemother Pharmacol 43: 69-71, 1999.

22. Schlueter C, Weber H, Meyer B, et al: Angiogenetic signaling through hypoxia: HMGB1: an angiogenetic switch molecule. Am J Pathol 166: 1259-12563, 2005.

23. Chuangui $\mathrm{C}$, Peng T and Zhentao Y: The expression of high mobility group box 1 is associated with lymph node metastasis and poor prognosis in esophageal squamous cell carcinoma. Pathol Oncol Res 18: 1021-1027, 2012.

24. Völp K, Brezniceanu ML, Bösser S, et al: Increased expression of high mobility group box 1 (HMGB1) is associated with an elevated level of the antiapoptotic c-IAP2 protein in human colon carcinomas. Gut 55: 234-242, 2006.

25. Dong YD, Cui L, Peng CH, et al: Expression and clinical significance of HMGB1 in human liver cancer: Knockdown inhibits tumor growth and metastasis in vitro and in vivo. Oncol Rep 29: 87-94, 2013.

26. Zeh HR 3rd and Lotze MT: Addicted to death: invasive cancer and the immune response to unscheduled cell death. J Immunother 28: 1-9, 2005.

27. Lindqvist A, Rouet P, Salier JP and Akerström B: The alpha1-microglobulin/bikunin gene: characterization in mouse and evolution. Gene 234: 329-336, 1999.

28. Kanayama N, Halim A, Maehara K, et al: Kunitz-type trypsin inhibitor prevents LPS-induced increase of cytosolic free $\mathrm{Ca}^{2+}$ in human neutrophils and HUVEC cells. Biochem Biophys Res Commun 207: 324-330, 1995. 
29. Kobayashi H, Gotoh J, Fujie M and Terao T: Characterization of the cellular binding site for the urinary trypsin inhibitor. J Biol Chem 269: 20642-20647, 1994.

30. Kobayashi $\mathrm{H}$, Shinohara $\mathrm{H}$, Ohi $\mathrm{H}$, et al: Urinary trypsin inhibitor (UTI) and fragments derived from UTI by limited proteolysis efficiently inhibit tumor cell invasion. Clin Exp Metastasis 12: 117-128, 1994.

31. Kobayashi H, Fujie M, Shinohara H, et al: Effects of urinary trypsin inhibitor on the invasion of reconstituted basement membranes by ovarian cancer cells. Int J Cancer 57: 378-384, 1994.

32. Kobayashi H, Sugino D and Terao T: Urinary trypsin inhibitor, a Kunitz-type protease inhibitor, modulates tumor necrosis factor-stimulated activation and translocation of protein kinase C in U937 cells. Int J Oncol 12: 95-105, 1998.

33. Tanaka R, Fujita M, Tsuruta R, et al: Urinary trypsin inhibitor suppresses excessive generation of superoxide anion radical, systemic inflammation, oxidative stress, and endothelial injury in endotoxemic rats. Inflamm Res 59: 597-606, 2010

34. Albini A, Iwamoto Y, Kleinman HK, et al: A rapid in vitro assay for quantitating the invasive potential of tumor cells Cancer Res 47: 3239-3245, 1987.

35. Ellerman JE, Brown CK, de Vera M, et al: Masquerader: high mobility group box-1 and cancer. Clin Cancer Res 13 2836-2848, 2007

36. Sasahira T, Akama Y, Fujii K and Kuniyasu H: Expression of receptor for advanced glycation end products and HMGB1/amphoterin in colorectal adenomas. Virchows Arch 446: 411-415, 2005

37. Ishiguro H, Nakaigawa N, Miyoshi Y, et al: Receptor for advanced glycation end products (RAGE) and its ligand, amphoterin are overexpressed and associated with prostate cancer development. Prostate 64: 92-100, 2005.

38. Xingjun Yao,Gang Zhao,Hongfa Yang, et al: Overexpression of high-mobility group box 1 correlates with tumor progression and poor prognosis in human colorectal carcinoma. J Cancer Res Clin Oncol 136: 677-684, 2010.

39. Yao X, Zhao G, Yang H, et al: Overexpression of high-mobility group box 1 correlates with tumor progression and poor prognosis in human colorectal carcinoma. J Cancer Res Clin Oncol 136 677-684, 2010.

40. Srikrishna G,Freeze HH: Endogenous damage-associated molecular pattern molecules at the crossroads of inflammation and cancer. Neoplasia11: 615-28, 2009.

41. Srikrishna G and Freeze HH: Endogenous damage-associated molecular pattern molecules at the crossroads of inflammation and cancer. Neoplasia 11: 615-628, 2009.

42. Le Bitoux MA and Stamenkovic I: Tumor-host interactions: the role of inflammation. Histochem Cell Biol 6: 1079-1090, 2008.

43. Kobayashi H, Shinohara H, Fujie M, et al: Inhibition of metastasis of Lewis lung carcinoma by urinary trypsin inhibitor in experimental and spontaneous metastasis models. Int J Cancer 63 455-462, 1995

44. Shu H, Liu K, He Q, et al: Ulinastatin, a protease inhibitor, may inhibit allogeneic blood transfusion-associated pro-inflammatory cytokines and systemic inflammatory response syndrome and improve postoperative recovery. Blood Transfus 109-118, 2014.
45. Kobayashi H, Suzuki M, Hirashima Y and Terao T: The protease inhibitor bikunin, a novel anti-metastatic agent. Biol Chem 384: 749-754, 2003.

46. Sun ZJ, Yu T, Chen JS, et al: Effects of ulinastatin and cyclophosphamide on the growth of xenograft breast cancer and expression of CXC chemokine receptor 4 and matrix metalloproteinase-9 in cancers. J Int Med Res 38: 967-976, 2010.

47. Palumbo R, Galvez BG, Pusterla T, et al: Cells migrating to sites of tissue damage in response to the danger signal HMGB1 require NF-kappaB activation. J Cell Biol 179: 33-40, 2007.

48. Wang H, Sun X, Gao F, et al: Effect of ulinastatin on growth inhibition, apoptosis of breast carcinoma cells is related to a decrease in signal conduction of JNk-2 and NF-kappaB. J Exp Clin Cancer Res 31: 2, 2012.

49. Brezniceanu ML, Völp K, Bösser S, et al: HMGB1 inhibits cell death in yeast and mammalian cells and is abundantly expressed in human breast carcinoma. Faseb J 17: 1295-1297, 2003.

50. Jones LG, Ella KM, Bradshaw CD, et al: Activations of mitogen-activated protein kinases and phospholipase D in A7r5 vascular smooth muscle cells. J Biol Chem 269: 23790-23799, 1994

51. Nguyen DH, Catling AD, Webb DJ, et al: Myosin light chain kinase functions downstream of Ras/ERK to promote migration of urokinase-type plasminogen activator-stimulated cells in an integrin-selective manner. J Cell Biol 146: 149-164, 1999.

52. Olson MF, Ashworth A and Hall A: An essential role for Rho, Rac, and Cdc42 GTPases in cell cycle progression through G1. Science 269: 1270-1272, 1995.

53. Kobayashi H, Suzuki M, Kanayama N, et al: Suppression of urokinase receptor expression by bikunin is associated with inhibition of upstream targets of extracellular signal-regulated kinase-dependent cascade. Eur J Biochem 269: 3945-3957, 2002.

54. Kang HJ, Lee H, Choi HJ, et al: Non-histone nuclear factor HMGB1 is phosphorylated and secreted in colon cancers. Lab Invest 89: 948-959, 2009.

55. Nishizuka Y: Intracellular signaling by hydrolysis of phospholipids and activation of protein kinase C. Science 5082: 607-614, 1992

56. Paolucci L and Rozengurt E: Protein kinase D in small cell lung cancer cells: rapid activation through protein kinase C. Cancer Res 3: 572-577, 1999.

57. Goode N, Hughes K, Woodgett R and Parker PJ: Differential regulation of glycogen synthase kinase-3 beta by protein kinase C isotypes. J Biol Chem 267: 16878-16882, 1992.

58. Burgering BM, de Vries-Smits AM, Medema RH, et al: Epidermal growth factor induces phosphorylation of extracellular signal-regulated kinase 2 via multiple pathways. Mol Cell Biol 13: 7248-7256, 1993

59. Wisniewski JR, Schulze E and Sapetto B: DNA binding and nuclear translocation of insect high-mobility-group-protein-1 (HMG1) proteins are inhibited by phosphorylation. Eur J Biochem 225: 687-693, 1994.

60. Kobayashi H, Suzuki M, Tanaka Y, et al: Suppression of urokinase expression and invasiveness by urinary trypsin inhibitor is mediated through inhibition of protein kinase $\mathrm{C}$ and MEK/ERK/c-Jun-dependent signaling pathways. J Biol Chem 276: 2015-2022, 2001. 